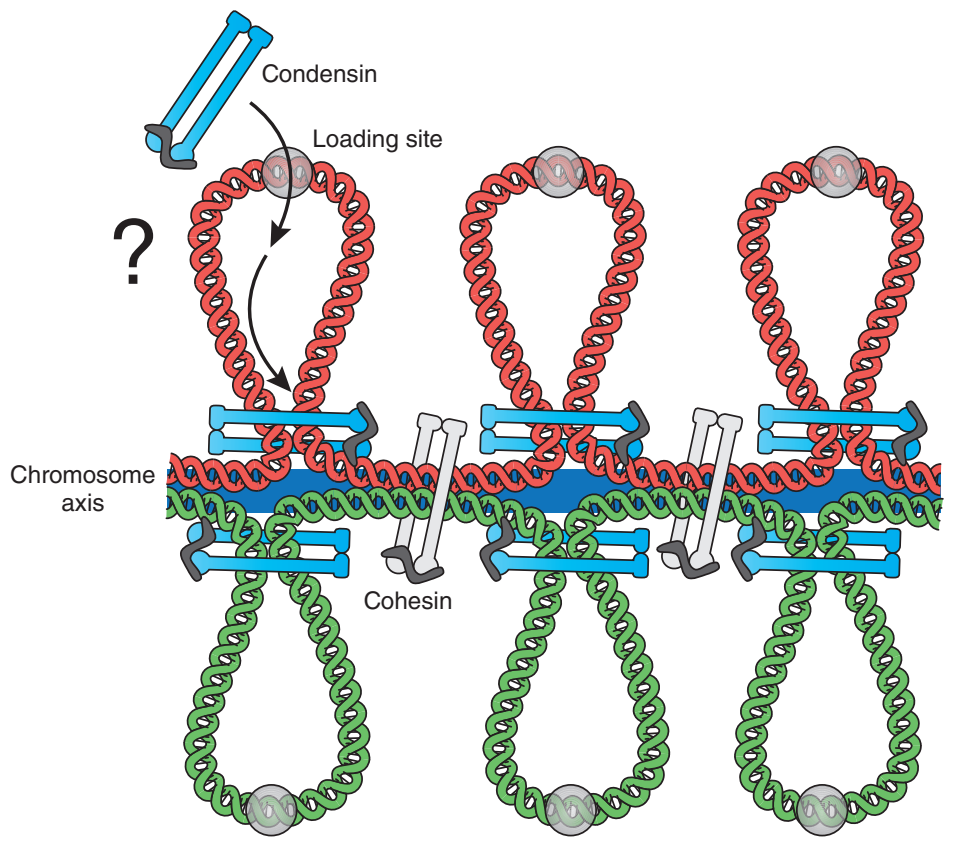

Figure 2 Putative scenario for formation of the mitotic chromosome. Condensin complexes are loaded at the future apices of DNA loops, which then emerge by DNA extrusion through the complex and determine a self-organizing chromosome axis.

matids, which would probably be detrimental to chromatid resolution in prophase and segregation in anaphase. A plausible and simple model would comprise two steps (Fig. 2): the initial loading of condensin onto an emerging loop of DNA and the subsequent extrusion of DNA until condensin hits the self-organizing chromosome axis ${ }^{23,24}$. The formation of topologically associating domains (TADs) might accordingly be brought about by the loading of cohesin or condensin onto DNA within a TAD and the extrusion of DNA until the domain boundaries are reached.

\section{COMPETING FINANCIAL INTERESTS}

The authors declare no competing financial interests.

1. Shintomi, K., Takahashi, T.S. \& Hirano, T. Nat. Cell Biol. 17, 1014-1023 (2015).

2. Houlard, M. et al. Nat. Cell Biol. 17, 771-781 (2015).

3. Wang, X. et al. Genes Dev. 29, 1661-1675 (2015).

4. Marbouty, M. et al. Mol. Cell 59, 588-602 (2015).

5. Marbouty, M. et al. eLife 3, e03318 (2014).

6. Le, T.B., Imakaev, M.V., Mirny, L.A. \& Laub, M.T. Science 342, 731-734 (2013).

7. Umbarger, M.A. et al. Mol. Cell 44, 252-264 (2011).

8. Wang, X., Montero Llopis, P. \& Rudner, D.Z. Nat. Rev. Genet. 14, 191-203 (2013).

9. Vallet-Gely, I. \& Boccard, F. PLoS Genet. $\mathbf{9}$, e1003492 (2013).

10. Hwang, L.C. et al. EMBO J. 32, 1238-1249 (2013).

11. Gruber, S. \& Errington, J. Cell 137, 685-696 (2009).

12. Sullivan, N.L., Marquis, K.A. \& Rudner, D.Z. Cel/ 137, 697-707 (2009)

13. Minnen, A., Attaiech, L., Thon, M., Gruber, S. \& Veening, J.W. Mol. Microbiol. 81, 676-688 (2011).

14. Wilhelm, L. et al. eLife 4, e06659 (2015)

15. de Laat, W. \& Dekker, J. Methods 58, 189-191 (2012).

16. Bürmann, F. et al. Nat. Struct. Mol. Biol. 20, 371-379 (2013).

17. Gligoris, T.G. et al. Science 346, 963-967 (2014).

18. Cuylen, S., Metz, J. \& Haering, C.H. Nat. Struct. Mol. Biol. 18, 894-901 (2011).

19. Gruber, S. Curr. Opin. Microbiol. 22, 102-110 (2014).

20. Hu, B. et al. Curr. Biol. 21, 12-24 (2011).

21. Gruber, S. et al. Curr. Biol. 24, 293-298 (2014).

22. Wang, X., Tang, O.W., Riley, E.P. \& Rudner, D.Z. Curr. Biol. 24, 287-292 (2014)

23. Nasmyth, K. Annu. Rev. Genet. 35, 673-745 (2001).

24. Alipour, E. \& Marko, J.F. Nucleic Acids Res. 40, 11202-11212 (2012)

\title{
PAR and the organization of the DNA damage response
}

Chains of poly(ADP-ribose), or PAR, are rapidly synthesized at DNA break sites and contribute to the DNA damage response, likely by recruiting repair factors. Now Altmeyer, Lukas and coworkers add another layer of complexity: they propose that PAR acts as a molecular seed to assemble intrinsically disordered proteins into dynamic, membranefree compartments at DNA damage sites (Nat. Commun. doi:10.1038/ncomms9088, published 19 August 2015).

The formation of such subcellular structures, for example the nucleolus or stress granules, was previously shown to involve specific RNA molecules and proteins containing low-complexity domains (LCDs), regions composed of repetitive motifs that are often intrinsically disordered. Assembly of these membrane-free compartments is akin to the formation of liquid droplets in an oil-water mixture-i.e., phase separation by liquid demixing.

An analysis of previous PAR-protein association data revealed an enrichment in proteins featuring LCDs. Given its chemical similarity to RNA, PAR could potentially have a similar effect in triggering phase separation. The authors test this hypothesis, focusing on three LCD-containing, PAR-associated proteins: FUS/TLS (fused in sarcoma/translocated in sarcoma), EWS (Ewing sarcoma) and TAF15 (TATA box-binding protein associated factor); these are collectively referred to as the FET proteins.

Using GFP fusions and inflicting DNA damage with laser microirradiation, the authors find that the FET proteins assemble at DNA damage sites in a PAR-dependent manner. The FET proteins have 2 types of LCDs, whose functions are dissected: the RGG-repeat module is recruited to PAR via electrostatic interactions, whereas the prion-like SYQG-rich module mediates phase separation and form assemblies at high concentrations. These structures are formed at DNA damage sites and could be directly observed in bright-field microscopy as zones showing distinct light diffraction properties (see right panel, black arrows; left panel shows fluorescence microscopy for GFP-EWS, with white arrows marking orientation of the laser). The assemblies include other LCD-containing proteins, but downstream DNA damage factors had differential access to the PAR-seeded compartments: while MDC1 could accumulate together with the FET proteins, 53BP1 was excluded.

These observations lead to a model whereby PAR, a polymer lacking sequence information, allows cells to compartmentalize specific proteins within the nucleus. By changing the physicochemical properties of the environment around chromosomal lesions, PAR-seeded transient microorganelles orchestrate, both temporally and spatially, the molecular events that engender DNA damage response and repair.

Inês Chen 